\title{
RLAV \\ O corpo em cena: reflexões interdisciplinares
}

Anselmo Peres Alós i Universidade Federal de Santa Maria

Enviado em: 09/06/18 - Aprovado em: 09/07/18

TAVARES, Enéias Farias; BIANCALANA, Gisela Reis; MAGNO, Mariane (Org.). Discursos do corpo na arte. v. II. Santa Maria: UFSM, 2017. 344p.

Qual o lugar do corpo nas artes? Essa pergunta gera respostas bastante diferentes, condicionadas, antes de qualquer coisa, pelo campo artístico no qual se situa o sujeito que a responde. Para alguém situado no campo dos estudos literários, o lugar do corpo pode ser o lugar do objeto representado pelo discurso ficcional; pode ser, também, o texto, entendido como a materialidade apreensível do objeto literário, o corpus. Para um performer ou um bailarino, o corpo é o próprio suporte de um discurso não verbal, ponto de partida para o movimento e a emersão da sintaxe dessa linguagem artística. Para um pintor, o corpo é quase sempre objeto da representação: reproduzido, questionado, problematizado ou desmembrado, ele dificilmente será visto como suporte, tal como é 
visto por performers e bailarinos. Para um ator, ele pode ser a superfície que modula a estruturação do trabalho, suporte para a estruturação da contraparte verbal de um espetáculo. Essa multiplicidade de percepções é o que caracteriza o conjunto de textos que compõe Discursos do corpo na arte, volume II. Como os discursos sobre o corpo, a arte e a cultura se alternam e se entrecruzam no campo interdisciplinar? Essa é a pergunta basilar que norteia os capítulos assinados por doze especialistas, importantes docentes e pesquisadores em seus respectivos campos, e que se encontram em atuação em diferentes instituições universitárias.

Em "O corpo na poesia de Emily Dickinson", Alcides Cardoso dos Santos (UNESPAraraquara) preocupa-se em discutir a obra da grande poeta estadunidense, levando em consideração "uma consciência da particularidade da escrita feminina resultante da percepção de que a relação das mulheres com o mundo", consciência essa "indispensável da sua experiência com o corpo" (p. 19). Santos dialoga com a crítica feminista, recuperando nomes já clássicos para sustentar suas análises, tais como os de Virginia Woolf, Hélène Cixous, Sandra Gilbert e Susan Gubar. O autor concentra seus esforços críticos em uma leitura "que trata da difícil relação de Dickinson com o corpo, que amiúde transparecerá em sua poesia na forma de obliteração, em gestos que vão da recusa à crueldade até a automutilação" (p. 29). Enéias Farias Tavares (UFSM), a seu turno, discute a representação iconográfica do corpo feminino na pintura, tomando como objeto de análise as esfinges que emergem na pintura de Franz Stuck. Para tanto, Tavares coloca quatro pinturas de Stuck em diálogo com a tradição literária que perpetuou o mito clássico de Édipo e seu confronto com a Esfinge. Nessa discussão, as ideias de Bram Dijkstra em Idols of perversity (Oxford: Oxford UP, 1986) recebem especial atenção. De acordo com Tavares, "ao silenciar a Esfinge, ao ignorar sua voz, sua identidade, sua feminilidade e a resposta ambígua exigida de um enigma igualmente ambíguo, o herói cede, fracassa, deturpa-se, condena-se, ironicamente pensando-se glorioso e soberano" (p. 51). No confronto entre a Esfinge e Édipo, o herói desvenda o enigma, levando a esfinge devoradora de homens ao suicídio, jogando-se ao mar. Ironicamente, é a vitória sobre a Esfinge que arrastará Édipo para o leito de sua própria mãe, Jocasta.

"O corpo presente: feminismo e performance de Shakespeare em Portugal", de Francesca Rainer (professora da Universidade do Minho), discute a presença do corpo das mulheres na dramaturgia de William Shakespeare, partindo das relações entre feminismo e performance, e tomando como corpus duas montagens portuguesas de Shakespeare: a comédia Sonho de uma noite de verão (encenada em 1996) e a tragédia Tito Andronicus 
(encenada em 2003). No ensaio de Rainer, merece particular atenção a articulação que a autora realiza entre o trabalho filosófico de Judith Butler nas searas do feminismo e as teorizações do teatro pós-dramático.

O entrelugar entre o palco e o texto literário também é assunto abordado por Mariane Magno (UFSM) em "um movimento espiralado sobre o processo criativo do espetáculo Matrimônio de céu e inferno", inspirado na obra homônima de William Blake. O processo de criação coreográfica e a busca pelo entendimento corporal foram mediados pela noção de imagem poéticaproposta nas teorias da imaginação simbólica de Gaston Bachelard. Ao longo do processo criativo, Magno propõe uma analogia entre o trabalho corporal e o método infernal, técnica de gravura utilizada por William Blake que consistia no tratamento de chapas de cobre com ácido para a criação de matrizes para a impressão de suas gravuras: "queríamos desde o primeiro momento corroer qualquer forma pronta, fácil, cheia de significado e vazia de sentido. Queríamos, sobretudo, despertar o corpo a partir do self corporal. Entendendo e vivendo, portanto, o corpo como território do inconsciente criador" (p. 99).

Luís Fernando Ramos (USP), que atualmente encontra-se preparando um volume antológico com textos de Gordon Craig, a ser publicado pela editora Perspectiva, de São Paulo, assina o capítulo "A relação entre atores e screens no teatro de Gordon Craig: um legado à contemporaneidade". Nesse trabalho, Ramos problematiza, no âmbito da contemporaneidade, o legado de Craig para as artes do espetáculo, dando ênfase aos projetos Scene e Übber-Marionette. De acordo com Ramos, para Craig "os atores teriam uma função menor, a de simplesmente emprestar seus corpos à entidade ÜbberMarionette, vestindo uma armadura, ou um exoesqueleto, e desempenhando alguns movimentos, mas limitados pelo artefato cênico e submetidos ao conjunto da cena" ( $p$. 129).

Em "De volta à cena após um acidente vascular cerebral: em busca de uma poética da diferença", Sílvia Susana Wolff, professora do curso de Dança da UFSM, discute o quanto sua percepção acerca da dança ampliou-se após ter sofrido um AVC. A partir do desenvolvimento de uma visão somática de seu corpo, desenvolvida enquanto se recuperava, Wolff discute, entre outros pontos, a questão das hierarquias nos processos de ensino/aprendizagem no campo da dança. Segundo ela, "a relação mestre/aluno que se estabelece no ensino do balé é permeada por uma extrema hierarquização que torna o professor, muitas vezes, intocável e inquestionável" (p. 151). Pensando nas relações que a prática da dança estabeleceu com a sua recuperação terapêutica, Wolff chega à 
seguinte conclusão: "o ato de imaginar é um aliado, e uma poderosa ferramenta, quando buscamos a poesia nos movimentos ou a recuperação de ações através da dança. A utilização da imagem e o processo de recordar a memória têm sido companheiros tanto no aprendizado da dança quanto em métodos somáticos" (p. 168).

Esse processo de produção de conhecimento nas zonas disciplinares das Artes do Espetáculo que lança mão de uma escrita em grande medida autobiográfica também é o caminho trilhado por Inês Alcaraz Marocco, que atuou como professora no curso de Teatro da UFSM durante muitos anos e, atualmente, leciona no Departamento de Artes Dramáticas da UFRGS. Em "Aventuras na academia; reflexões sobre uma prática artística/pedagógica", Marocco discute a sua trajetória formativa como docente de artes dramáticas. A autora faz uma pertinente problematização da dissociação entre prática artística e pensamento teórico no contexto da universidade brasileira, onde "predomina o trabalho acadêmico que mais 'informa' do que 'forma' artisticamente os alunos" (p. 179). Wolff pergunta-se: "como ter uma experiência artística em sala de aula? Como romper com a exclusividade da interpretação nas universidades e oferecer momentos de presença? E como isso se reflete na produção bibliográfica dos cursos de Artes brasileiros, mais especificamente? O que se valoriza mais é refletir e teorizar sobre as práticas. E é aí que começam as nossas dificuldades" (p. 179).

Encerrando sua discussão, a autora conclui que "precisamos nos conscientizar e lutar por uma instituição [universitária] que nos represente, que valorize a real função da nossa área que é a de fazer teatro, e não escrever sobre, teorizar sobre" (p. 215). A presença do corpo nas artes performativas é o mote da discussão apresentada pela professora Gisela Reis Biancalana (UFSM) em "O corpo-arte performativo na contemporaneidade". De acordo com Biancalana, "a corporeidade cênica está voltada para construções poéticas, e o investimento válido a ser realizado deveria ter profundidade e, especialmente, deveria ser voltado para si, para a vida, para além da técnica e do objetivo imediato da cena performativa" (p. 230).

Tal como o ser humano, em perpétua transformação, a autora salienta que o processo formativo de um performer nunca acaba, uma vez que "acompanha o percurso formativo dos performers durante sua vida na arte" (p. 230). Tendo isso em vista, a autora faz uma entusiasmada defesa da adoção de perspectivas interdisciplinares na prática docente que visa à formação de atores e performers. 
Em "Claro/escuro: (anti)teatralidades contemporâneas", Arthur Belloni, docente do Departamento de Artes Cênicas da UFSM, discute os limites entre a teatralidade e a antiteatralidade, partindo do lugar que o corpo ocupa nas artes do espetáculo. Para ele, "a performance acaba, nesse sentido, configurando uma máquina que opera a partir de significantes seriados: pedaços de corpo [...] e também pedaços de sentidos, fluxos libidinais, nacos de objetos, conectados ou não através de estruturas narrativas, mas antes por meio de concatenações multipolares" (p. 246). Partindo do trabalho performativo realizado pelo e sobre o corpo do artista, Belloni discute as possibilidades, os caminhos e as problemáticas articulações na concepção de um teatro sem ficção.

"Quando o corpo discorre em dança, qual a língua?". Essa é a pergunta a que Tatiana Wonsnik Recompenza Joseph tenta responder em seu texto, que toma a pergunta como título. Professora de dança na UFSM, Joseph discute as possibilidades gestuais no encontro da linguagem da dança com a língua brasileira de sinais, tema que ela já havia abordado em livro publicado em 2012, sob o título a língua de sinais e a escuta sensível, publicado em Saabrucken, pela Editorial Académica Española. Para Joseph, "o ato de escrever é um gesto poético do existir" (p. 270); a autora afirma ainda que "o conceito de composição coreográfica, quando visto sob a perspectiva etimológica, pode ser compreendido como o trabalho de escrever ou 'grafar' uma escrita no corpo, ou através do corpo, e essa 'escrita' constitui o próprio ato de 'compor'"' (p. 273).

Heloisa Gravina, em "Eu tenho um corpo, eu sou um corpo: experiências com abordagens somáticas do movimento no Bacharelado em Dança", recupera a experiência da escrita automática desenvolvida pelos surrealistas, aplicando-a em suas experiências com relação ao trabalho de consciência corporal. Para tanto, Gravina (que atua como professora na UFSM) lança mão de seus diários de trabalho, discutindo tanto suas próprias anotações acerca dos seus processos criativos quanto de suas práticas docentes, no sentido de produzir conhecimento a partir de um exercício dialógico que combina escrita, experimentação corporal e reflexão coletiva junto com seus alunos.

Encerrando o volume, o capítulo assinado por Marcia Strazzacappa, intitulado "Das memórias inscritas no corpo", relata as experiências da autora, enfocando a questão do ensino de dança na formação de profissionais de outras áreas do conhecimento. Strazzacappa, que é docente da UNICAMP e Bolsista de Produtividade em Pesquisa do CNPq, narra como se deu o processo de criação da disciplina Teatro para aperfeiçoamento da relação médico-paciente, oferecida na grade curricular dos cursos de graduação da área da saúde (Medicina, Enfermagem e Fonoaudiologia) da UNICAMP. 
Para ela, "a prática de dança demanda o desenvolvimento de uma consciência corporal e amplia as capacidades do corpo, logo, do indivíduo. A dança amplia o potencial de adaptação do corpo, de resposta ao meio, de diálogo com o espaço e com o corpo do outro" (p. 329-330). Discutindo alguns dos vínculos possíveis entre a educação somática, a prática artística da dança e a formação profissional na área da saúde, Strazzacappa tece as seguintes considerações: "o trabalho corporal e artístico que proponho não tem por público o paciente, e sim o profissional, seja ele professor, médico, enfermeiro. Acredito cada vez mais que se a arte estivesse presente na vida dos indivíduos, independentemente de sua profissão, teríamos cidadãos melhores e, por consequência, um mundo melhor" (p. 331).

Reiterando uma vez mais, Discursos do corpo na arte (volume II) revela-se um conjunto de estudos indispensável, referência obrigatória para pesquisadores, docentes e estudantes no campo das Artes e das Humanidades, em especial para aqueles que trabalham e escrevem o corpo, sobre o corpo ou com o corpo.

\footnotetext{
' Doutor em Literatura Comparada. Professor do Departamento de Letras Vernáculas da Universidade Federal de Santa Maria. Docente permanente do Programa de PósGraduação em Letras da mesma instituição. Bolsista de Produtividade em Pesquisa do CNPq (PQ-2).
}

Como citar essa resenha:

ALÓS, Anselmo Peres. O corpo em cena: reflexões interdisciplinares. Revista Digital do LAV, Santa Maria: UFSM, v. 11, n. 3, p. 162-167, set./dez. 2018. 